\title{
1.PP
}

\section{Influence of the ventilatory mode on acute adverse effects and facial thermography after noninvasive ventilation}

\author{
Suzy Maria Montenegro Pontes ${ }^{1}$, Luiz Henrique de Paula Melo², \\ Nathalia Parente de Sousa Maia ${ }^{3}$, Andrea da Nóbrega Cirino Nogueira ${ }^{3}$, \\ Thiago Brasileiro Vasconcelos ${ }^{4}$, Eanes Delgado Barros Pereira ${ }^{5}$, \\ Vasco Pinheiro Diógenes Bastos ${ }^{3}$, Marcelo Alcantara Holanda ${ }^{5}$
}

1. Universidade Federal do Ceará Fortaleza (CE) Brasil.

2. Curso de Fisioterapia, Faculdade de Tecnologia Intensiva, Fortaleza (CE) Brasil.

3. Curso de Fisioterapia, Centro Universitário Estácio do Ceará, Fortaleza (CE) Brasil.

4. Programa de Pós-Graduação em Fisiologia e Farmacologia, Faculdade de Medicina, Universidade Federal do Ceará, Fortaleza (CE) Brasil.

5. Departamento de Medicina Clínica e Programa de Pós-Graduacão do Mestrado em Ciências Médicas, Universidade Federal do Ceará, Fortaleza (CE) Brasil.

Submitted: 21 June 2016.

Accepted: 18 November 2016

Study carried out in the Laboratório da Respiração - Resplab - Universidade Federal do Ceará, Fortaleza (CE) Brasi.

\begin{abstract}
Objective: To compare the incidence and intensity of acute adverse effects and the variation in the temperature of facial skin by thermography after the use of noninvasive ventilation (NIV). Methods: We included 20 healthy volunteers receiving NIV via oronasal mask for $1 \mathrm{~h}$. The volunteers were randomly divided into two groups according to the ventilatory mode: bilevel positive airway pressure (BiPAP) or continuous positive airway pressure (CPAP). Facial thermography was performed in order to determine the temperature of the face where it was in contact with the mask and of the nasal dorsum at various time points. After removal of the mask, the volunteers completed a questionnaire about adverse effects of NIV. Results: The incidence and intensity of acute adverse effects were higher in the individuals receiving BiPAP than in those receiving CPAP (16.1\% vs. $5.6 \%)$. Thermographic analysis showed a significant cooling of the facial skin in the two regions of interest immediately after removal of the mask. The more intense acute adverse effects occurred predominantly among the participants in whom the decrease in the mean temperature of the nasal dorsum was lower $(14.4 \%$ vs. $7.2 \%)$. The thermographic visual analysis of the zones of cooling and heating on the face identified areas of hypoperfusion or reactive hyperemia. Conclusions: The use of BiPAP mode was associated with a higher incidence and intensity of NIV-related acute adverse effects. There was an association between acute adverse effects and less cooling of the nasal dorsum immediately after removal of the mask. Cutaneous thermography can be an additional tool to detect adverse effects that the use of NIV has on facial skin.
\end{abstract}

Keywords: Masks; Noninvasive ventilation; Thermography.

\section{INTRODUCTION}

The use of noninvasive ventilation (NIV) in acute respiratory failure is associated with a reduced need for tracheal intubation, decreased length of hospital stay, and decreased mortality. ${ }^{(1-3)}$

NIV intolerance is one of the reasons for NIV failure. ${ }^{(4,5)}$ NIV failure can occur in $5-40 \%$ of cases, being associated with a 4-fold greater likelihood of in-hospital mortality-NIV failure (OR $=3.95 ; 95 \% \mathrm{CI}: 1.74-8.99) .{ }^{(6)}$ Interface-related problems are the most common adverse effects, accounting for $50-100 \%$ of all complications, such as excessive air leaks, discomfort caused by air pressure on the face, claustrophobia, rebreathing of carbon dioxide, skin lesions, facial pain, and oronasal dryness. ${ }^{(7)}$ Acute adverse effects are related to the type of mask and the pressure settings. ${ }^{(8,9)}$

Rates for the incidence of facial skin lesions resulting from the use of NIV masks range from $10-31 \%$ in adults. ${ }^{(10)}$ Pediatric studies have reported a $60 \%$ incidence of pressure ulcers associated with the use of medical devices, including masks for NIV. ${ }^{(11)}$ The incidence of pressure ulcers on the face and in the area of the nasal dorsum has been reported to be approximately $17 \%$. $^{(12)}$ The area of the nasal dorsum, with its scarce subcutaneous cellular tissue and its poor vascularization, is more likely to develop severe skin lesions because it is subject to greater contact pressure with the oronasal mask. ${ }^{(13)}$

Infrared skin thermometry or thermography is the most efficient means to study skin temperature distribution, by means of measurement of the temperature variations caused by greater or lesser irrigation of the microvascular territory. ${ }^{(14,15)}$ Thermography has contributed to the diagnosis and intensity monitoring of various conditions in which skin temperature may reflect an inflammatory process in the underlying tissues or may indicate where the blood flow may increase or decrease. ${ }^{(16)}$

The hypotheses of the present study were as follows: NIV-related variables (ventilatory mode and pressure settings) have an effect on local skin microcirculation in the zones of contact between the skin and the mask, changing the temperature levels of the facial skin tissue in these zones; and these possible temperature changes in the contact areas are measurable by infrared thermography and can be related to acute adverse effects. 
The objective of the present study was to compare the incidence and intensity of acute adverse effects and the variation in facial skin temperature between NIV modes-continuous positive airway pressure (CPAP) vs. bilevel positive airway pressure (BiPAP)-and to analyze the relationship between acute adverse effects of the application of NIV via oronasal mask and the variations in facial skin temperature in two areas: the zones of contact between the face and the mask; and the nasal dorsum.

\section{METHODS}

This was a prospective, analytical intervention study in humans. It was carried out in the Respiratory Laboratory of the Universidade Federal do Ceará (UFC, Federal University of Ceará) between March of 2014 and December of 2015. The sample consisted of 20 individuals (18-45 years of age) who were selected by convenience from among the participants in the Respiratory Laboratory and the student body of the UFC campus and who agreed to participate in the study. There were no dropouts or exclusions. All individuals participated in ventilatory mode randomization. The exclusion criteria were as follows: being under dermatological treatment for skin lesions or making use of creams or any type of chemical substance on the face; being on corticosteroids, anti-inflammatory drugs, or antihistamines; having an axillary temperature outside the normal range $\left(36.5^{\circ} \mathrm{C}-36.8^{\circ} \mathrm{C}\right)$; having excessive sun exposure, which was previously defined by the researchers as direct, unprotected sun exposure for more than 30 min before starting the experiment; and having a neurological disease, diabetes mellitus, nutritional disorders, or dehydration. The study was submitted to and approved by the UFC Research Ethics Committee (CAAE 20060113.4.0000.5045).

\section{Study protocol}

All participants were assessed by the same dermatologist of the UFC Department of Clinical Medicine, who used a specific, dermatological assessment form to check skin integrity and determine skin type and subsequently performed the first thermographic measurement.

Randomization was performed as follows: 20 labels reading either BiPAP or CPAP were placed into an opaque container; and the participants themselves drew a label out of the container.

After this randomization, the ventilator was set up-CPAP $=10 \mathrm{cmH}_{2} \mathrm{O}$ or BiPAP; expiratory positive airway pressure (EPAP) $=5 \mathrm{cmH}_{2} \mathrm{O}$; inspiratory positive airway pressure (IPAP) $=20 \mathrm{cmH}_{2} \mathrm{O}$; and pressure support $=15 \mathrm{cmH}_{2} \mathrm{O}$-and the choice of interface to minimize air leak was made on the basis of the anatomical characteristics of the volunteer's face. The Mirage Quattro FX mask (ResMed, Bella Vista, Australia), which is an oronasal interface equipped with an exhalation valve, was the model made available to the participants.
Subsequently, the mask was gently placed on the participant's face and was connected to the NIV ventilator; the entire system was checked for the presence of leaks, and the necessary corrections were made.

We used two dedicated, single-limb NIV ventilators that can be set in CPAP mode and BiPAP mode, both equipped with a memory card to record data during therapy, without a humidifier. The Auto VPAP (ResMed) was set in BiPAP mode, with an EPAP of $5 \mathrm{cmH}_{2} \mathrm{O}$ and an IPAP of $20 \mathrm{cmH}_{2} \mathrm{O}$; the Autoset II (ResMed) was set in CPAP mode, with a fixed pressure of $10 \mathrm{cmH}_{2} \mathrm{O}$. ${ }^{(17)}$

The individual remained seated for an initial 10-min period of adaptation to NIV, which was then continued for an additional $50 \mathrm{~min}$, totaling $60 \mathrm{~min}$ of NIV.

Immediately after removal of the mask, the second thermographic measurement was performed, and, to prevent any kind of influence by the team, the participants then viewed their own faces in a high-definition digital photographic image in order to complete a questionnaire about NIV-related adverse effects, with a score ranging from zero (no problem) to three (intense problem). ${ }^{(18)}$ The adverse effects were grouped into three categories: skin lesions; pain; and other adverse effects (Appendix 1; available in the online version of the JBP; http://www.jornaldepneumologia. com.br/detalhe_anexo.asp?id=49). Subsequently, thermographic images were taken at 5, 15, and 30 min after removal of the mask, with the participants in the same posture and under the same conditions as those of the previous measurements.

The memory cards of the ventilators were read with ResScan software (ResMed) in order to record leaks occurring around the mask.

The thermographic images taken with a VarioCAM thermographic camera (InfraTec, Jena, Germany) were stored in the memory card of the camera and analyzed with IRBIS ${ }^{\circledR}$ Professional analysis software for thermographic images, version 2.2 (InfraTec). The thermographic images were converted and transferred to MATLAB ${ }^{\circledR}$ simulation software, version 2015a (MathWorks, Natick, MA, USA). On the basis of a reference point established by a piece of styrofoam glued between the participant's eyebrows (Figure 1A), the regions of interest in the original images were cut out in the shape of a trapezoid (Figures $1 \mathrm{~B}$ and $1 \mathrm{C}$ ). By means of a specific script, a color-based comparative analysis of the temperature variation in the zones of contact between the skin and the mask was carried out by superimposing the images taken at each of the time points after removal of the mask on those taken at baseline. The room where the protocols were performed was kept well lit at a temperature of $22^{\circ} \mathrm{C}$ (range, $21.5^{\circ} \mathrm{C}-22.5^{\circ} \mathrm{C}$ ) and at a relative humidity of $60 \%$ (range, $57.94 \%-60.26 \%$ ). The variation in room temperature did not exceed $1^{\circ} \mathrm{C}$ over the 20 -min period.

\section{Statistical analysis of variables}

For descriptive statistics, means and standard deviations or medians and interquartile ranges were 
calculated for quantitative variables, depending on the sample distribution. Categorical variables were expressed as absolute and relative frequencies. Categorical parameters were compared by means of Fisher's exact test. Since the scoring of adverse effects resulted from a subjective finding by each volunteer, we chose to group the adverse effects into three categories. ${ }^{(18)}$

The variation in mean temperature was compared between the two ventilatory modes (CPAP vs. BiPAP) and between the two regions of interest (zone of contact between the nasal dorsum and the mask vs. zone of contact between the face and the mask) by ANOVA, depending on the normality of test results. In addition, Pearson's correlation coefficient between skin temperature and adverse effects was analyzed. The level of statistical significance required to reject the null hypothesis was set at $5 \%(p<0.05)$.

\section{RESULTS}

Table 1 shows the participant demographic characteristics and the room environmental conditions, by ventilatory mode. The sample consisted of 20 volunteers with a mean age of $28.15 \pm 8.08$ years ( $95 \%$ CI: 20.07-36.23); the anthropometric characteristics (mean BMI of $23.57 \pm 2.51 \mathrm{~kg} / \mathrm{m}^{2}$ and mean axillary temperature of $36.39^{\circ} \mathrm{C}$ ) were homogeneous. The room environmental conditions were kept under control (mean relative humidity of $59.1 \pm 116 \%$ and mean room temperature of $22.1 \pm 0.31^{\circ} \mathrm{C}$ ). The mean air leak measured by the NIV ventilator during NIV was $2.30 \pm 3.19 \mathrm{~L} / \mathrm{min}$.

Dermatological assessment showed no dermatological lesions, facial malformations, or changes in touch or pain sensitivity. Skin elasticity was preserved. The oval face shape predominated, being found in $80 \%$ of the individuals receiving CPAP and in $90 \%$ of those receiving BiPAP. Skin color was light brown in $80 \%$ of the volunteers. Skin type was oily in $70 \%$ of the individuals.

Table 2 shows the results of the scores for adverse effects in three predefined categories, by ventilatory mode. The effects causing a greater degree of problem or discomfort during BiPAP ventilation were pruritus on the nose, claustrophobia, dryness, and nasal congestion, whereas, during CPAP ventilation, none of the adverse effects reached the maximum degree of discomfort.

When comparing the participants' answers regarding the intensity of each adverse effect individually, by ventilatory mode, we found no significant differences; however (Figure 2A), when grouping the participants' answers to all categories of adverse effects, we found a significant difference in occurrence of the more intense adverse effects in BiPAP mode. We significantly found that moderate and intense adverse effects (scores 2 and 3 ) were more common immediately after removal of the mask in the group of participants in whom there was no reduction in the temperature of the nasal dorsum (Figure $2 \mathrm{~B}$ ). There was a statistically significant decrease in the mean temperature of the nasal dorsum, as compared
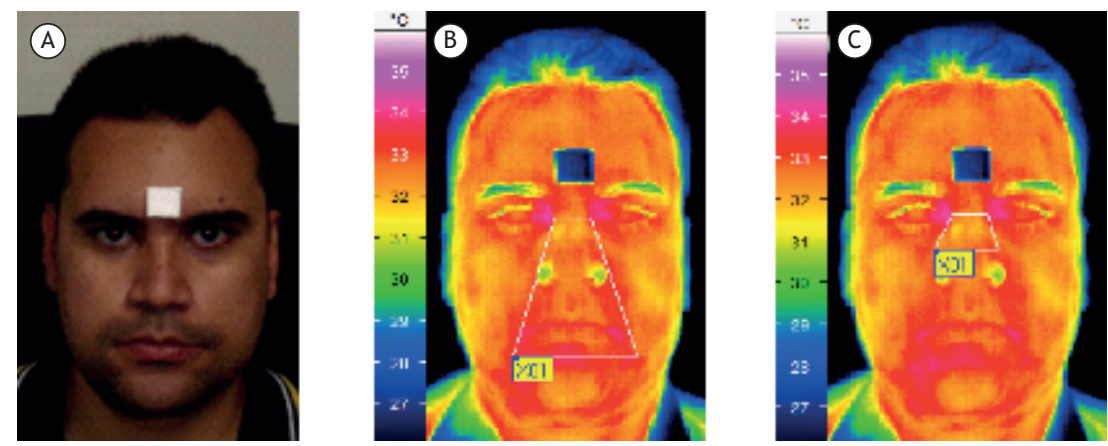

Figure 1. Conventional photograph (in A) and thermographic images of the areas of contact between the face and the mask (in B) and between the nasal dorsum and the mask (in C).

Table 1. Participant demographic characteristics and room environmental conditions, by ventilatory mode. ${ }^{a}$

\begin{tabular}{lccc}
\multicolumn{1}{c}{ Characteristic } & $\begin{array}{c}\text { BiPAP } \\
(\mathbf{n}=\mathbf{1 0})\end{array}$ & $\begin{array}{c}\text { CPAP } \\
(\mathbf{n}=\mathbf{1 0})\end{array}$ & $\begin{array}{c}\text { Total } \\
\text { (N }=20)\end{array}$ \\
\hline Age, years & $27.4 \pm 9.20$ & $28.9 \pm 7.20$ & $28.15 \pm 8.08$ \\
Weight, $\mathrm{kg}$ & $66.3 \pm 11.09$ & $69.38 \pm 16.84$ & $67.84 \pm 13.97$ \\
Height, $\mathrm{m}$ & $1.69 \pm 0.07$ & $1.68 \pm 0.12$ & $1.68 \pm 0.09$ \\
BMl, $\mathrm{kg} / \mathrm{m}^{2}$ & $22.92 \pm 2.13$ & $24.23 \pm 2.80$ & $23.57 \pm 2.51$ \\
Axillary temperature, ${ }^{\circ} \mathrm{C}$ & $36.4 \pm 0.39$ & $36.39 \pm 0.29$ & $36.39 \pm 0.34$ \\
Male gender, $\mathrm{n}(\%)$ & $5(50)$ & $5(50)$ & $10(50)$ \\
Relative humidity, $\%$ & $59.3 \pm 1.16$ & $58.9 \pm 1.19$ & $59.1 \pm 1.16$ \\
Room temperature, ${ }^{\circ} \mathrm{C}$ & $22.14 \pm 0.30$ & $22.06 \pm 0.33$ & $22.1 \pm 0.31$ \\
Air leak, L/min & $2.16 \pm 1.56$ & $2.83 \pm 4.31$ & $2.32 \pm 3.19$ \\
\hline
\end{tabular}

BiPAP: bilevel positive airway pressure; and CPAP: continuous positive airway pressure. aValues expressed as mean $\pm S D$, except where otherwise indicated. 
Table 2. Classification of adverse effect intensity in the participants, by ventilatory mode. ${ }^{\text {a }}$

\begin{tabular}{|c|c|c|c|c|}
\hline \multirow[t]{3}{*}{ Adverse effect } & \multicolumn{4}{|c|}{ Ventilatory mode } \\
\hline & \multicolumn{2}{|c|}{$\operatorname{BiPAP}(n=10)$} & \multicolumn{2}{|c|}{ CPAP $(n=10)$} \\
\hline & No or mild & $\begin{array}{l}\text { Moderate or } \\
\text { intense }\end{array}$ & No or mild & $\begin{array}{l}\text { Moderate or } \\
\text { intense }\end{array}$ \\
\hline \multicolumn{5}{|l|}{ Category 1 - Skin lesions } \\
\hline Erythema on the cheek & $9(90)$ & $1(10)$ & $10(100)$ & $0(0)$ \\
\hline Erythema on the nasal dorsum & $5(50)$ & $5(50)$ & $6(60)$ & $4(40)$ \\
\hline Erythema on the chin & $9(90)$ & $1(10)$ & $9(90)$ & $1(10)$ \\
\hline Pruritus on the cheek & $8(80)$ & $2(20)$ & $10(100)$ & $0(0)$ \\
\hline Pruritus on the nose & $7(70)$ & $3(30)$ & $9(90)$ & $1(10)$ \\
\hline Pruritus on the chin & $8(80)$ & $2(20)$ & $10(100)$ & $0(0)$ \\
\hline \multicolumn{5}{|l|}{ Category 2 - Pain } \\
\hline Nasal dorsum & $9(90)$ & $1(10)$ & $9(90)$ & $1(10)$ \\
\hline Ear & $8(90)$ & $2(20)$ & $10(100)$ & $0(0)$ \\
\hline Paranasal sinuses & $9(90)$ & $1(10)$ & $10(100)$ & $0(0)$ \\
\hline Cheek & $9(90)$ & $1(10)$ & $10(100)$ & $0(0)$ \\
\hline Chin & $10(100)$ & $0(0)$ & $10(100)$ & $0(0)$ \\
\hline Head & $10(100)$ & $0(0)$ & $9(90)$ & $1(10)$ \\
\hline \multicolumn{5}{|l|}{ Category 3 - Other adverse effects } \\
\hline Claustrophobia & $9(90)$ & $1(0)$ & $10(100)$ & $0(0)$ \\
\hline Air leak & $8(80)$ & $2(20)$ & $10(100)$ & $0(0)$ \\
\hline Dryness & $6(60)$ & $4(40)$ & $9(90)$ & $1(10)$ \\
\hline Nasal congestion & $8(80)$ & $2(20)$ & $10(100)$ & $0(0)$ \\
\hline Respiratory distress & $9(90)$ & $1(10)$ & $9(90)$ & $1(10)$ \\
\hline Chest discomfort & $10(100)$ & $0(0)$ & $10(100)$ & $0(0)$ \\
\hline
\end{tabular}

BiPAP: bilevel positive airway pressure; and CPAP: continuous positive airway pressure. ${ }^{a}$ Data expressed as $n(\%)$.

with baseline, immediately, at $5 \mathrm{~min}$, at $15 \mathrm{~min}$, and at 30 min after removal of the mask. Figure $3 \mathrm{~A}$ depicts the mean temperature in the areas of contact between the face and the mask and between the nasal dorsum and the mask before and immediately after $60 \mathrm{~min}$ of NIV, as well as at 5, 15, and 30 min after removal of the mask. We observed a significantly different behavior between the two areas. In the area of contact between the face and the mask immediately after removal of the mask, there was a decrease in temperature; however, at the subsequent time points (at 5, 15, and $30 \mathrm{~min}$ after removal of the mask), there was a trend toward a return to baseline values. In the area of contact between the nasal dorsum and the mask, there was a decrease in mean temperature immediately after removal of the mask, and the cooling persisted at the subsequent time points. Figure $3 \mathrm{~B}$ depicts the temperature variation in the area of the nasal dorsum by ventilatory mode. We observed that the decrease in temperature persisted in CPAP mode.

In the qualitative assessment (Figure 4 ) of the superimposed images taken before NIV and at each of the other time points (immediately, at $5 \mathrm{~min}$, at $15 \mathrm{~min}$, and at 30 min after removal of the mask), we found that the blue color (maximum cooling) predominated in CPAP mode and the red color (maximum heating) predominated in BiPAP mode.

There were no statistically significant correlations between adverse effects and the temperature variation in the two regions of interest when Pearson's correlation coefficient was used (See table in Appendix 2 ; available in the online version of the JBP; http:// www.jornaldepneumologia.com.br/detalhe_anexo. asp?id=49).

\section{DISCUSSION}

The incidence and intensity of acute adverse effects resulting from the use of NIV (claustrophobia, dryness, and nasal congestion) were higher in the participants receiving BiPAP than in those receiving CPAP. Thermographic analysis of the oronasal region showed cooling in the area of contact between the facial skin and the mask and in the area of the nasal dorsum immediately after removal of the mask. The area of the nasal dorsum varied less relative to the baseline temperature, showing less cooling than the zone of contact between the facial skin and the mask. In the area of contact between the facial skin and the mask, the temperature gradually returned to its baseline value, that is, it increased at the subsequent time points. Visual analysis of the zones of cooling and heating on the face over time showed coexisting areas of hypoperfusion or reactive hyperemia from acute use of NIV after removal of the mask, with a trend toward an increase in temperature in the group receiving BiPAP.

The more intense acute adverse effects assessed immediately after removal of the mask occurred 

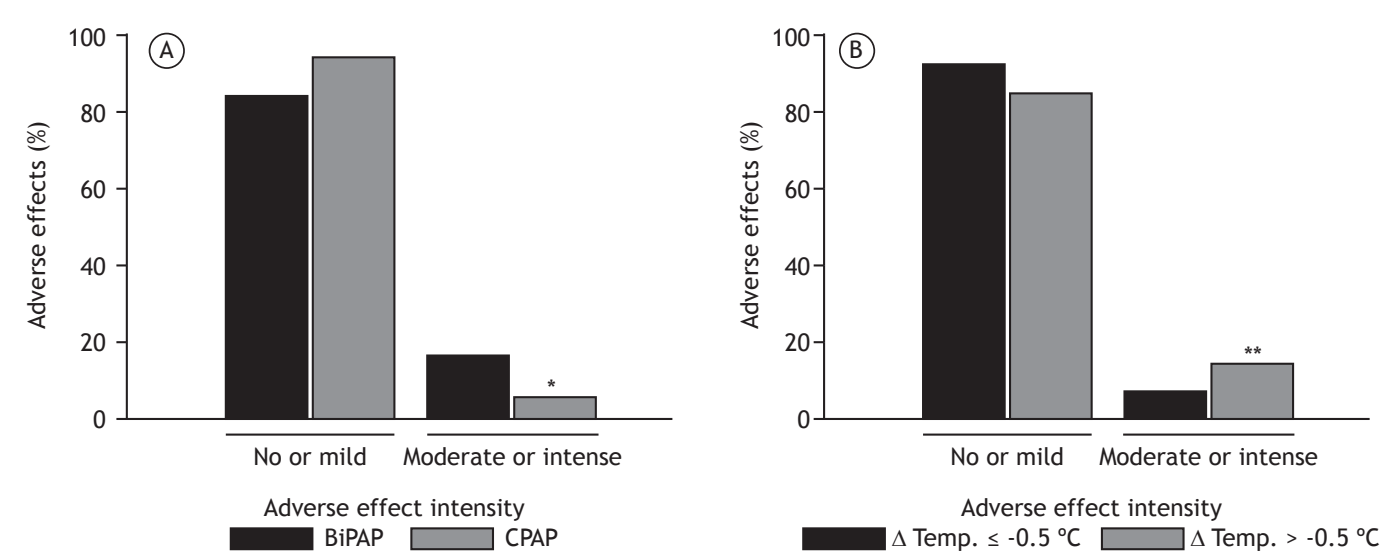

Figure 2. In A, proportion of participant-reported adverse effects by ventilatory mode. In B, proportion of participantreported adverse effects by temperature variation in the area of the nasal dorsum immediately after removal of the mask. $\triangle$ Temp: temperature variation between baseline and immediately after removal of the mask; BiPAP: bilevel positive airway pressure; and CPAP: continuous positive airway pressure. $* p=0.001 ; * * p=0.04$. Total number of reported adverse events $=360$.
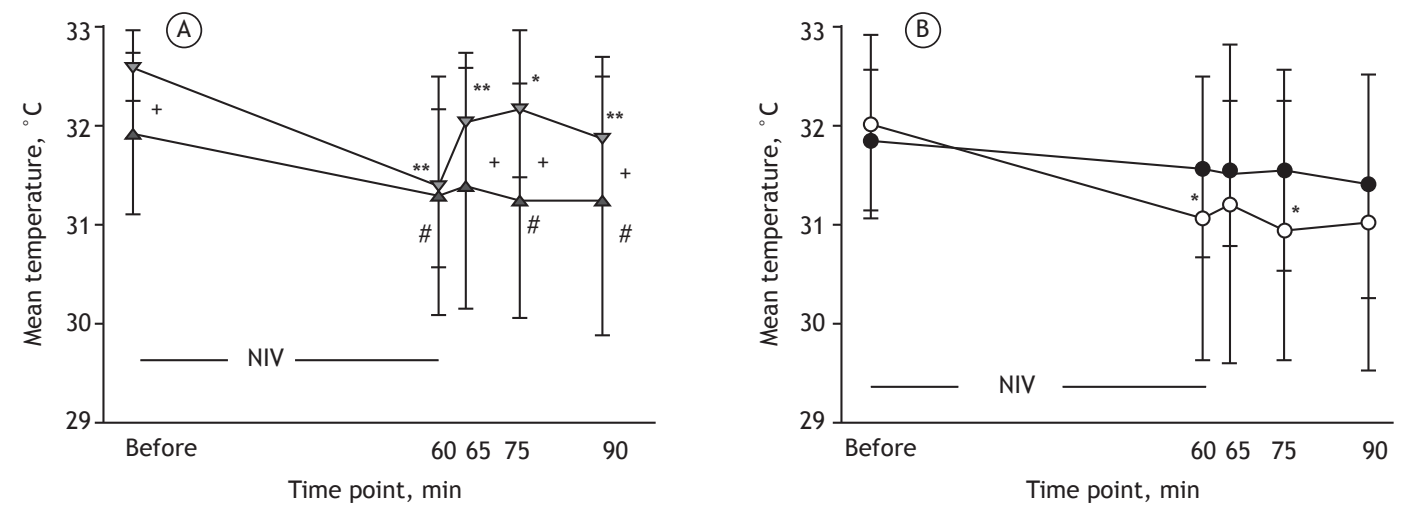

Figure 3. In A, mean temperature in the areas of contact between the face and the mask (inverted triangles) and between the nasal dorsum and the mask (gray triangles) before and immediately after 60 min of noninvasive ventilation (NIV), as well as at $5 \mathrm{~min}(65 \mathrm{~min}), 15 \mathrm{~min}(75 \mathrm{~min})$, and $30 \mathrm{~min}(90 \mathrm{~min})$ after removal of the mask. In B, mean temperature in the area of contact between the nasal dorsum and the mask at the same time points, by ventilatory mode-bilevel positive airway pressure (black circles) and continuous positive airway pressure (white circles). Figure $3 \mathrm{~A}: * p<0.05$ and $* * p<0.01$ vs. baseline temperature; ${ }^{+} p<0.05$ area of contact between the nasal dorsum and the mask vs. area of contact between the face and the mask; ${ }^{\# p}<0.05$ area of contact between the nasal dorsum and the mask vs. baseline temperature. Figure $3 \mathrm{~B}:{ }^{*} \mathrm{p}<0.05$ continuous positive airway pressure mode vs. baseline.

among the participants in whom the nasal dorsum skin showed less cooling.

The present study is the first to use thermographic analysis of the facial skin before and after the use of NIV at various time points and to test the association of these findings, for BiPAP and CPAP, with acute adverse effects. The facial skin temperature data of the present study are consistent with those obtained by Haddad et al., ${ }^{(19)}$ demonstrating the validity of our methodology.

Holanda et al.(8) studied three types of masks and the acute adverse effects related to their use by comparing two different NIV pressure settings in healthy individuals: a lower pressure setting (IPAP $=$ $11 \mathrm{cmH}_{2} \mathrm{O}$ and EPAP $=6 \mathrm{cmH}_{2} \mathrm{O}$ ); and a higher pressure setting (IPAP $=15 \mathrm{cmH}_{2} \mathrm{O}$ and EPAP $=10 \mathrm{cmH}_{2} \mathrm{O}$ ). The increase in pressure increased the incidence of acute adverse effects for the three masks. It is possible to infer that, in the present study, BiPAP was associated with a higher incidence and intensity of acute adverse effects, as compared with CPAP, probably because of higher levels of IPAP $\left(20 \mathrm{cmH}_{2} \mathrm{O}\right.$ vs. $\left.10 \mathrm{cmH}_{2} \mathrm{O}\right)$.

Although microcirculation in the area of contact between the mask and the skin was not subjected to direct measurement, it may have been compromised by decreased blood supply (immediately after removal of the mask), which would result in cooling of the contact area, probably caused by pressure ischemia; subsequently, the temperature returned to its baseline values or even surpassed them, resulting in heating of the area, presumably because of reactive hyperemia. In the area of the nasal dorsum, initially there was a smaller decrease in mean temperature relative to the baseline temperature. On average, there was no return to the baseline values (before NIV); however, in some individuals, heating occurred in this area, 


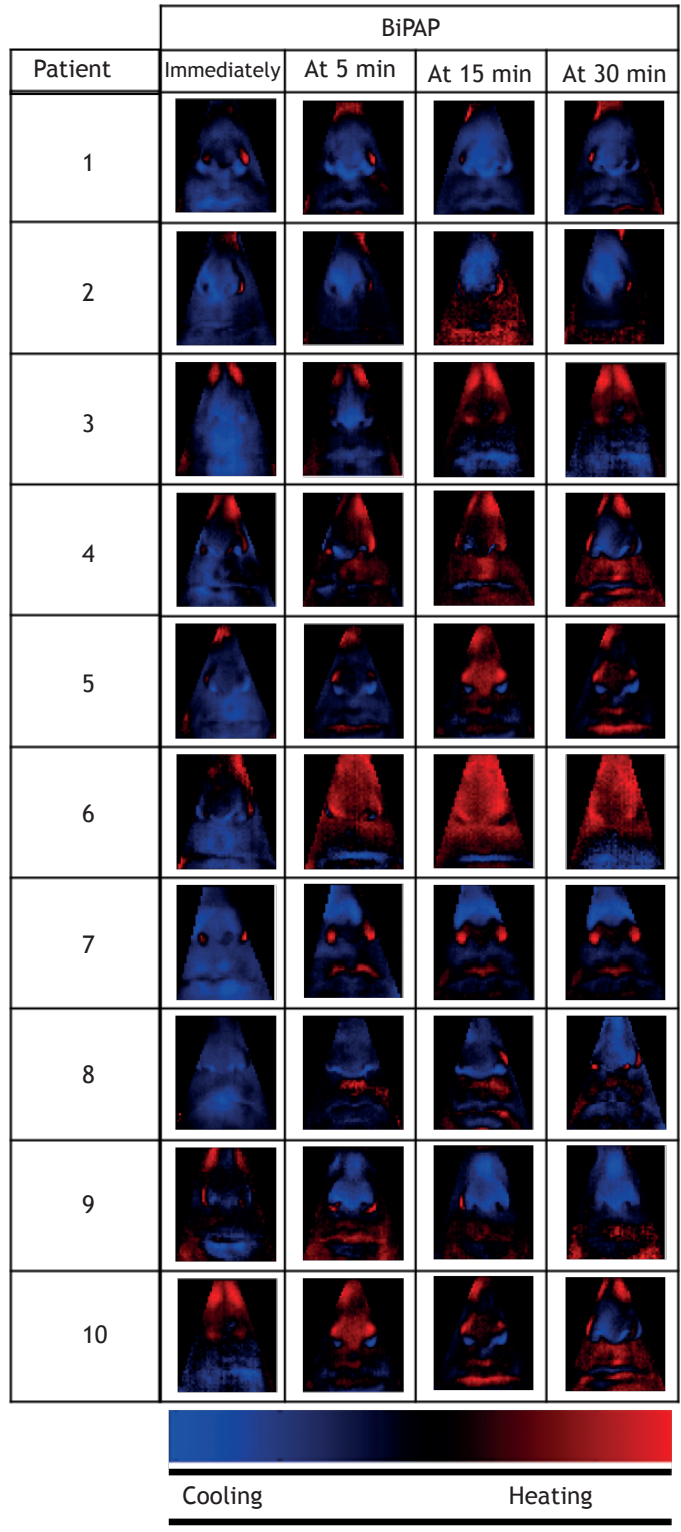

For the same superimposed image

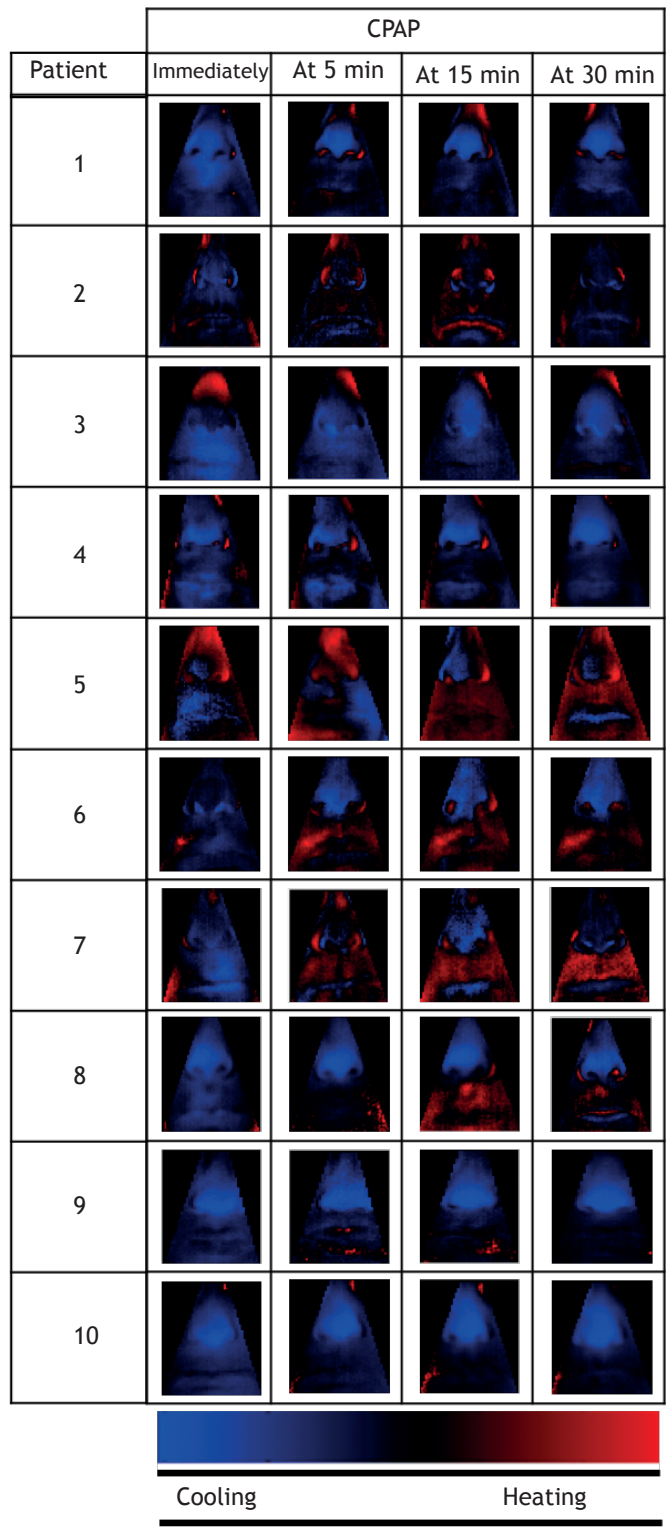

For the same superimposed image

Figure 4. Qualitative assessment of the superimposed images taken before noninvasive ventilation and at each of the other time points: immediately, at $5 \mathrm{~min}$, at $15 \mathrm{~min}$, and at $30 \mathrm{~min}$ after removal of the mask. The visual color bar scale ranging from maximum cooling (blue) to maximum heating (red) was used for each superimposed image. BiPAP: bilevel positive airway pressure; and CPAP: continuous positive airway pressure.

demonstrating that the response to the application of NIV is quite individual and varied.

The phenomenon of reactive hyperemia would explain the findings of the present study, or the poor vascularization of the cutaneous territory of the nasal dorsum would be a reason for the smaller impact of the mask pressure on the temperature variation in this area. Visual analysis of the zones of cooling and heating on the face over time showed that the response to the application of NIV is quite individual and varied.

Capillary perfusion pressure plays an important role in skin tissue integrity. The pressures leading to capillary collapse usually range from 12 to 32 $\mathrm{mmHg}$ or from 20 to $40 \mathrm{cmH}_{2} \mathrm{O}$. Direct application of a higher pressure than capillary closing pressure on the skin and soft tissues will cause hypoxia in the area, culminating in tissue ischemia and anoxia. (20) By removing pressure after a short period of time, blood flow is restored through reactive hyperemia. If there is prolonged, persistent application of pressure, the risk for ischemic injury increases, which might cause the onset of a pressure ulcer. ${ }^{(21)}$ In the present study, there was a higher incidence of more intense acute adverse events in the group of participants with a smaller decrease in the mean temperature of the 
nasal dorsum, emphasizing the predisposition of this particular area to skin perfusion disturbances. Souto et al. ${ }^{(13)}$ emphasized that the oronasal mask has severa areas that are subject to critical tension values for the development of skin lesions, the most relevant being in the upper lateral region of the nose.

Weng, ${ }^{(22)}$ seeking preventive measures against the development of skin lesions in patients using face masks for BiPAP ventilation, found a proportion of $96 \%$ of stage I pressure ulcers with hyperemia on the nasal dorsum, which is in line with data from clinical studies in terms of the susceptibility of the area of the nasal dorsum to skin lesions, including its anatomical characteristic of a thin layer of poorly vascularized epidermis covering the bone surface.

We concluded that the incidence and intensity of acute adverse effects were higher in the participants receiving BiPAP ventilation. There was an association between acute adverse effects of the application of NIV via oronasal mask and less cooling or greater reactive hyperemia in the area of the nasal dorsum after removal of the mask. Thermography can be an additional tool to detect skin areas at high risk of developing skin lesions.

Methodological rigor in preparing the environment and the participants and a literature review on the optimal conditions to perform thermography are the strengths of this study. However, the study has limitations. The sample was small, involving healthy participants, and the results would probably be different in situations in which other risk factors (age, nutritional status, medication use, presence of comorbidities, and level of consciousness) were present. ${ }^{(12,21,23)}$ Another important limitation was the lack of a control group receiving heated humidification. $(24,25)$

The practical implication is to underscore the importance of monitoring acute adverse effects on the skin of patients receiving NIV. The use of pressure masks is associated with the development of facial skin lesions, probably because of impaired perfusion. (26-29) Thermography would be an additional tool for more accurate determination of facial skin areas at high risk of NIV-related pressure lesions or ulcers. Therefore, the results stimulate interest in future clinical trials assessing this perspective.

\section{REFERENCES}

1. Ferreira S, Nogueira C, Conde S, Taveira N. Non-invasive ventilation [Article in Portuguese]. Rev Port Pneumol. 2009;15(4):655-67. https://doi.org/10.1016/S0873-2159(15)30162-8

2. Crimi $C$, Noto A, Princi $P$, Esquinas A, Nava S. A European survey of noninvasive ventilation practices. Eur Respir J. 2010;36(2):362-9. https://doi.org/10.1183/09031936.00123509

3. Barbas CS, Isola AM, Farias AM, Cavalcanti AB, Gama AM, Duarte $A C$, et al. Brazilian recommendations of mechanical ventilation 2013. Part I. Rev Bras Ter Intensiva. 2014; 26(2):89-121. https://doi. org/10.5935/0103-507X.20140017

4. Liu J, Duan J, Bai L, Zhou L. Noninvasive Ventilation Intolerance: Characteristics, Predictors, and Outcomes. Respir Care 2016;61(3):277-84. https://doi.org/10.4187/respcare.04220

5. Nava $S$, Ceriana P. Causes of failure of noninvasive mechanical ventilation. Respir Care. 2004;49(3):295-303

6. Azevedo LC, Park M, Salluh JI, Rea-Neto A, Souza-Dantas VC Varaschin $\mathrm{P}$, et al. Clinical outcomes of patients requiring ventilatory support in Brazilian intensive care units: a multicenter, prospective, cohort study. Crit Care. 2013;17(2):R63. https://doi.org/10.1186/ cc12594

7. Mehta S, Hill NS. Noninvasive ventilation. Am J Respir Crit Care Med 2001;163(2):540-77. https://doi.org/10.1164/ajrccm.163.2.9906116

8. Holanda MA, Reis RC, Winkeler GF, Fortaleza SC, Lima JW, Pereira ED. Influence of total face, facial and nasal masks on short-term adverse effects during noninvasive ventilation. J Bras Pneumol. 2009;35(2):164-73. https://doi.org/10.1590/S180637132009000200010

9. Keenan SP, Winston B. Interfaces for noninvasive ventilation: does it matter? J Bras Pneumol. 2009;35(2):103-5. https://doi.org/10.1590/ S1806-37132009000200001

10. Schallom M, Cracchiolo L, Falker A, Foster J, Hager J, Morehouse $T$, et al. Pressure Ulcer Incidence in Patients Wearing Nasal-Oral Versus Full-Face Noninvasive Ventilation Masks. Am J Crit Care. 2015;24(4):349-56; quiz 357. https://doi.org/10.4037/ajcc2015386

11. Visscher MO, White CC, Jones JM, Cahill T, Jones DC, Pan BS Face Masks for Noninvasive Ventilation: Fit, Excess Skin Hydration, and Pressure Ulcers. Respir Care. 2015;60(11):1536-47. https://doi. org/10.4187/respcare.04036

12. Black J, Alves $P$, Brindle CT, Dealey C, Santamaria N, Call E, et al. Use of wound dressings to enhance prevention of pressure ulcers caused by medical devices. Int Wound J. 2015:12(3):322-7. https:// doi.org/10.1111/iwj.12111

13. Souto $L$, Talaia $P$, Ramos $A$, Silva $N$, Drummond $M$, Jorge RN. Análise da interface da máscara oronasal em um modelo de face humana. Proceedings of the 10th Congresso Ibero-Americano de Engenharia Mecânica; 2011 Sep 4-7; Porto, Portugal. CIBEM; 2011.

14. Brioschi ML, Macedo JF, Macedo RA. Termometria cutânea: novos conceitos. J Vasc Bras. 2003;2:151-60

15. Lahiri BB, Bagavathiappan S, Jayakumar T, Philip J. Medical applications of infrared thermography: A review. Infrared Phys.Technol. 2012:55:221-35. https://doi.org/10.1016/j. infrared.2012.03.007

16. Fernández-Cuevas I, Bouzas-Marins JC, Arnáiz-Lastras J, GómezCarmona PM, Pi-onosa-Cano S, García-Concepción MA, et al. Classification of factors influencing the use of infrared thermography in humans: a review. Infrared Phys Technol. 2015;71:28-55. https:// doi.org/10.1016/j.infrared.2015.02.007

17. Schettino GP, Reis MA, Galas F, Park M, Franca S, Okamoto V. Ventilação mecânica não invasiva com pressão positiva. J Bras Pneumol. 2007:33(Suppl 2):92-105. https://doi.org/10.1590/S180637132007000800004

18. Reis RC. Estudo comparativo do conforto e efeitos adversos de interfaces para ventilação não invasiva em voluntários sadios. [dissertation]. Fortaleza: Universidade Federal do Ceará; 2006.

19. Haddad DS, Brioschi ML, Baladi MG, Arita ES. A new evaluation of heat distribution on facial skin surface by infrared thermography. Dentomaxillofac Radiol. 2016;45(4):20150264. https://doi. org/10.1259/dmfr.20150264

20. Medeiros $A B$, Lopes $C H$, Jorge MS. Analysis of prevention and treatment of the pressure ulcers proposed by nurses [Article in Portuguese]. Rev Esc Enferm USP 2009;43(1):223-8. https://doi. org/10.1590/S0080-62342009000100029

21. Caliri MH. Feridas crônicas, prevenção e tratamento. [monograph on the Internetl. Ribeirão Preto: Escola de Enfermagem de Ribeirão Preto, Universidade de São Paulo; 2010 [cited 2016 May 8]; Available from: http://www2.eerp.usp.br/site/grupos/feridascronicas/index php

22. Weng MH. The effect of protective treatment in reducing pressure ulcers for non-invasive ventilation patients. Intensive Crit Care Nurs. 2008;24(5):295-9. https://doi.org/10.1016/j.iccn.2007.11.005

23. Gomes FS, Bastos MA, Batista JA, Velásquez-Meléndez G. Analysis of agreement of the evaluation of pressure ulcer staging [Article in Portuguese]. Rev Min Enferm. 2013:17(2):14-17. https://doi. org/10.5935/1415-2762.20130020 
24. Esquinas-Rodriguez AM, Scala R, Soroksky A, BaHammam A, de Klerk A, Valipour A, et al. Clinical review: humidifiers during noninvasive ventilation-key topics and practical implications. Crit Care. 2012;16(1):203. https://doi.org/10.1186/cc10534

25. Terabe DS. Umidificação das vias aéreas em UTI: como uma padronização de atendimento altera o uso dos umidificadores. [dissertation]. São Paulo: Fundação Antônio Prudente; 2006.

26. Yamaguti WP, Moderno EV, Yamashita SY, Gomes TG, Maida AL, Kondo CS, et al. Treatment-related risk factors for development of skin breakdown in subjects with acute respiratory failure undergoing noninvasive ventilation or CPAP. Respir Care. 2014;59(10):1530-6. https://doi.org/10.4187/respcare.02942

27. Galvez AT, Oliva MI, Alonso AR, Alvarez AA. Ventilación no invasiva con pressión positiva. Rev Cubana Med. 2002;41(1):29-44.

28. Sferrazza Papa GF, Di Marco F, Akoumianaki E, Brochard L. Recent advances in interfaces for non-invasive ventilation: from bench studies to practical issues. Minerva Anestesiol. 2012;78(10):1146-53.

29. Ahmad Z, Venus M, Kisku W, Rayatt SS. A case series of skin necrosis following use of non invasive ventilation pressure masks. Int Wound J. 2013;10(1):87-90. https://doi.org/10.1111/j.1742-481X.2012.00948.X 